\title{
Educação física e tecnologia: o processo de "tecnização" educacional, Evandro Antonio Corrêa, Dagmar Hunger Curitiba, Appris, 2020. 229 p. (Educação, tecnologias e transdisciplinaridade).
}

\author{
(iD) Priscila Fátima da Silva Fiel \\ Mestranda em educação na UNINOVE. \\ Professora de Educação Física na Prefeitura Municipal de Jundiaí, SP, Brasil. \\ priscila.fiel@hotmail.com
}

O livro Educação física e tecnologia: o processo de "tecnização" educacional, organizado em quatro capítulos, discute as inquietações sobre a utilização de tecnologias tanto por professores quanto por alunos, dentro das temáticas de educação física. A nomenclatura “tecnização” é utilizada mediante diferentes discursos no ensino escolar.

O prefácio, escrito por Thais Cristina Rodrigues Tezani, destaca a inserção tecnológica no espaço e tempo na educação física contemporânea e a apresentação da obra aponta as experiências e estratégias tecnológicas utilizadas no processo de ensino e aprendizagem, em diferentes nuances na educação do ensino fundamental II, desmistificando a "modinha" e agregando a utilização de novas tecnologias com o intuito de desenvolver diferentes saberes na educação. Os autores se baseiam nas ideias de Norbert Elias (2006), Pierre Lévy (1999), que compreendem a tecnização como processo civilizatório que se configura entre sociedade, tecnologia e indivíduos.

No primeiro capítulo intitulado "Delineamentos da pesquisa e método de abordagem", Corrêa e Hunger discutem como o ser humano se envolveu e se envolve com a tecnologia e sobre as pessoas que não têm acesso à linguagem tecnológica. Para a coleta de dados da pesquisa contaram com a participação de nove professores, sendo dois de Educação Física, três de Língua Portuguesa, três de História e um de Ciências. O estudo foi realizado com 238 alunos que cursam do sexto ao nono ano do ensino fundamental, e foram utilizados como recursos a sala de informática e computadores.

Segundo os autores, a escola, cenário da pesquisa, como espaço tecnológico, limitava-se à sala de informática e à sala de multimídia. Após solicitação, a equipe gestora autorizou a utilização 
de tablets e celulares nas aulas e foi feito um questionário sobre o emprego destes aparelhos. Evidenciou-se que o maior conhecimento dos alunos está vinculado às redes sociais, jogos e vídeos.

A partir dessa verificação foram aplicadas atividades de conhecimento sobre o corpo (conteúdo da educação física) mediado por jogos educativos, jogos eletrônicos e redes sociais. A linha de estudo foi sobre ótica conceitual, procedimental e atitudinal. A proposta durou dois semestres e meio, e, no final do segundo semestre, houve aplicação de novo questionário para alunos e professores. Para a realização das atividades foram disponibilizados links, whatsapp, pixton (história em quadrinhos) Google drive, ebook, escola digital, sites, facebook. Cada grupo os utilizava de acordo com sua necessidade. As técnicas de pesquisa dos alunos foram: questionário, fonte documental, entrevista e observação.

Para caracterização de pesquisa-ação houve intervenção constante com alunos e professores. O questionário foi composto por perguntas fechadas e abertas para os alunos e professores. O roteiro realizado para os alunos envolvia perguntas sobre as tecnologias utilizadas e como (e se) propiciavam a aprendizagem; para os professores foram utilizadas perguntas sobre a inserção das tecnologias em sua formação, e se nos últimos cinco anos houve participação em formação continuada que tinha como tema tecnologias.

No capítulo segundo, denominado "Processo de "tecnização" e educação: a figuração das tecnologias no contexto escolar", Corrêa e Hunger discorrem sobre a civilização que compreende as transformações do comportamento humano durante a história. É apresentado o processo de civilização que se refere como uma variedade de fatos, tecnologias diferentes e maneiras de conhecimento, sendo a tecnologia uma extensão do ser humano que afeta ricos e pobres.

No terceiro capítulo "Configurações no espaço escolar e a inserção das tecnologias no processo de ensino e aprendizagem", os autores propõem que deve haver uma compreensão dos processos humanos e um desenvolver de conhecimentos mais sólidos, e para isso, precisa-se estudar interdependência e estrutura de sociedade. Corrêa e Hunger citando Koehler e Mishra (2006) apresentam a teoria Conhecimento Tecnológico Pedagógico de Conteúdo (TPACK) apontando que a tecnologia não é somente algo a ser aprendida pelo docente, mas sim, vista como um conjunto de representações de conhecimentos dos professores nas disciplinas que utilizam as Tecnologias da Informação e Comunicação (TICs) em sala de aula.

No quarto e último capítulo intitulado "Saberes, necessidades e desafios percebidos pelos professores no ensino e aprendizagem com a tecnologia", os autores descrevem sobre a logística da escola, que ficará do jeito que já está: a sala, giz, lápis, cadernos e que o saber tecnológico não 
FIEL, Priscila Fátima da Silva. Educação física e tecnologia: o processo de "tecnização" educacional, Evandro Antonio Corrêa, Dagmar Hunger.

Resenha

pode se separar dos outros conhecimentos pertencentes ao professor, pois esse saber está atrelado à sua identidade e experiência de vida. Para a atualidade, segundo os autores, são necessários conhecimentos básicos (mínimos) das tecnologias para dar aula, pois os alunos não têm hábito de pesquisa e não utilizam os recursos tecnológicos continuamente. Nesse capítulo, Corrêa e Hunger também discutem o conceito de corpo civilizado construído pela presença de pais e professores, do outro e pela expressão de emoções.

Em suma, o livro traz uma discussão bastante interessante sobre inserções e apropriação das tecnologias na educação, o que nos faz refletir o quanto recursos tecnológicos bem empregados à escola podem aumentar a produtividade das aulas. A tecnização educacional ainda está em desenvolvimento e em constante movimento, porém, um cuidado se faz necessário para que o papel do professor não se resuma a ser um facilitador que satisfaz os modismos dos alunos.

Recebido em: 09 maio 2020 / Aprovado em: 06 jul. 2020

\section{Cite como:}

\section{(ABNT NBR 6023:2018)}

FIEL, Priscila Fátima da Silva. Educação física e tecnologia: o processo de "tecnização" educacional, Evandro Antonio Corrêa, Dagmar Hunger. Dialogia, São Paulo, n. 35, maio/ago. 2020. Resenha, p. 283-290. Disponível em: https://doi.org/10.5585/dialogia.n35.17180.

\section{American Psychological Association (APA)}

Fiel, P. F. da S. (2020, maio/ago.). Educação física e tecnologia: o processo de "tecnização" educacional, Evandro Antonio Corrêa, Dagmar Hunger. Resenha. Dialogia, São Paulo, 35, p. 283-290. https://doi.org/10.5585/dialogia.n35.17180. 